\title{
Comparison of low- and high-dose recombinant activated factor VII for postcardiac surgical bleeding
}

\author{
Aly Makram Habib ${ }^{1,2}$
}

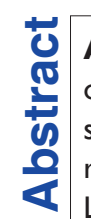

Aim of the Study: A retrospective observational study to compare safety and efficacy of high and low doses of recombinant activated factor VIla ( $r F V l l a)$ in severe postcardiac surgical bleeding. Patients and Methods: From 2004 to 20I4, all patients who received rFVIla for bleeding after cardiac surgery were included and arranged in two groups; Group I:

Low dose $(40-50 \mathrm{mcg} / \mathrm{kg})(n=98)$ and Group 2: High dose $(90-120 \mathrm{mcg} / \mathrm{kg})(n=156)$

Results: There was no significant difference in demographic and surgical characteristics of both groups on admission to Cardiac Surgical Intensive Care Unit (CSICU). There was no significant difference between the two groups regarding the reduction in chest tube bleeding in the first $6 \mathrm{~h}$ or the transfusion requirement in the $24 \mathrm{~h}$ after admission to CSICU.A total of 15 patients (5.9\%) had thromboembolic adverse events. (Seven (7.1\%) patients in Group I compared to $8(5.1 \%)$ patients in Group 2, $P=0.58)$. There were no significant differences in all-cause mortality at 30 days ( $2 \%$ in Group I vs. $3.2 \%$ in Group 2, $P=0.6)$ and at hospital discharge between the two study groups $(6.1 \%$ in Group I vs. $8.3 \%$ in Group 2, $P=0.5$ ), respectively. There was no significant difference between the two groups regarding the need for re-exploration, days on mechanical ventilation, CSICU, or hospital stay. Conclusion: In this report, Low-dose rFVIla showed equivalent efficacy and safety to high-dose rFVlla. Further prospective randomized studies are needed to confirm these findings.

Keywords: Bleeding, cardiac surgery, low dose, recombinant activated factor VIla

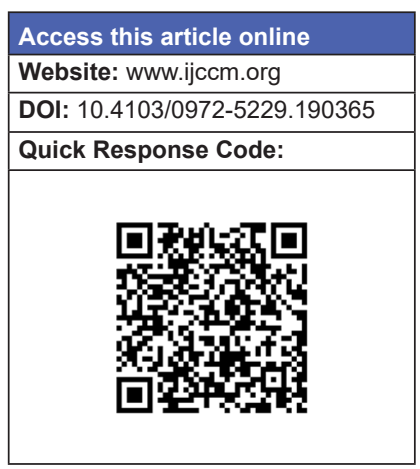

\section{Introduction}

Severe bleeding occurs in $10 \%-15 \%$ of patients undergoing cardiac surgical procedures..$^{[1-3]}$ This small subset of the cardiac surgical population, account for $80 \%$ of all blood products transfused during cardiac surgery ${ }^{[4,5]}$ Many require massive transfusion and/or re-exploration, both of which are associated with marked increases in morbidity and mortality. ${ }^{[2,6,7]}$

\section{From:}

1Department of Intensive Care, Adult Cardiac Intensive Care Unit, Prince Sultan Cardiac Centre, Prince Sultan Military Medical City, Riyadh, Saudi Arabia, ${ }^{2}$ Department of Critical Care Medicine, Faculty of Medicine, Cairo University, Cairo, Egypt

\section{Correspondence:}

Dr. Aly Makram Habib, Department of Intensive Care, Adult Surgical Intensive Care Unit, Prince Sultan Cardiac Center, Prince Sultan Military Medical City, Post Office Box 7897-X966, Riyadh 11159, Saudi Arabia.

E-mail: amhabib72@ hotmail.com

${ }^{*}$ Corresponding author was working at King Faisal Heart Center till June 2015 before he moves to: Intensive Care Department, Adult Surgical Intensive Care Unit, Prince Sultan Cardiac Center, Prince Sultan Military Medical City,

Post Office Box 7897-X966, Riyadh 11159, Saudi Arabia.
The use of hemostatic rescue agents, such as recombinant activated factor VIIa (rFVIIa; Novo Nordisk, Bagsvaerd, Denmark), has been accepted for achieving hemostasis when conventional therapy has failed. Many studies have reported that $\mathrm{rFVIIa}$ is a safe and effective treatment for hemorrhage after cardiac surgery. ${ }^{[8-10]}$ However, a clear benefit-risk profile for the use of agents such as rFVIIa is lacking. ${ }^{[11-14]}$

The optimal dosing regimen for rFVIIa in the postcardiac surgical setting remains unclear. The

This is an open access article distributed under the terms of the Creative Commons Attribution-NonCommercial-ShareAlike 3.0 License, which allows others to remix, tweak, and build upon the work non-commercially, as long as the author is credited and the new creations are licensed under the identical terms.

For reprints contact: reprints@medknow.com

How to cite this article: Habib AM. Comparison of low- and high-dose recombinant activated factor VII for postcardiac surgical bleeding. Indian J Crit Care Med 2016;20:497-503. 
reported dose range for single bolus administration has been broad (11.1-180 mcg/ $\mathrm{kg}$ ). Recommendations made by various expert panels have suggested doses in the order of $40-100 \mathrm{mcg} / \mathrm{kg}$ in the setting of uncontrolled postcardiac surgical hemorrhage, ${ }^{[8]}$ and the use of a low dose has been accepted in most institutions. ${ }^{[15,16]}$

rFVIIa dosage is not based on and cannot be monitored by available laboratory testing. Coagulation tests such as the prothrombin time and activated partial thromboplastin time are reported to be shortened in vitro this may not reflect in vivo effect of the drug on the patients' coagulation system at their own body temperature. The conventional measurement of FVIIa in the plasma after rFVIIa administration only proves the presence of FVIIa and its successful administration but does not predict any effect on hemostasis. ${ }^{[17]}$ This makes the only available way to study rFVIIa and determine its appropriate dose is through the effect on outcomes such as a decrease in bleeding, transfusion requirement, and surgical reexploration. This is not fully representative since these effects involve other coagulation system components as well.

The aim of this work is to show the difference in safety and efficacy between both low and high doses of rFVIIa when given to patients with severe postcardiac intractable surgical bleeding at the end of a step-by-step protocol to control bleeding at our institute.

\section{Patients and Methods}

The study was conducted in the cardiac surgical intensive care unit, (CSICU), King Faisal Heart Center, King Faisal Specialist Hospital and Research Center, Riyadh, Saudia Arabia.

\section{Patients}

Retrospectively, the medical charts of all adult patients who had cardiac surgery in the period between January 2004 and December 2014 were screened for the administration of rFVIIa for postoperative bleeding in the Intensive Care Unit (ICU) $(n=287)$. Patients who were < 18-year-old, pregnant females, have a history of primary coagulation defect, had a history of peripheral vascular disease, received rFVIIa in the operating room, having surgery for corrections of congenital heart diseases, requiring mechanical circulatory support, were excluded $(n=33)$ from the study. All patients who received rFVIIa in the Cardiac Surgical ICU (CSICU) for postoperative bleeding $(n=254)$ were included in the study. The patients were arranged in two groups according to the dose of rFVIIa given to them, Group 1: Low dose $(40-50 \mathrm{mcg} / \mathrm{kg})(n=98)$ and Group 2: High dose $(90-120 \mathrm{mcg} / \mathrm{kg})(n=156)$.
The study protocol was approved by the Institutional Research Center and Ethics Committees (RAC \#2121076). Being retrospective chart review study, consent was waived by the ethical committee.

Patients' demographics, preoperative comorbidities, preoperative anticoagulation, priority of surgery, type of surgery, cardiopulmonary bypass time, aortic cross-clamp time, and surgical re-exploration were collected. The European System for Cardiac Operative Risk Evaluation II score system was used to assess the severity for each patient. ${ }^{[18]}$

The primary endpoints of this work were to compare both groups regarding:

1. The efficacy defined as:

a. The amount of bleeding from chest tube

b. The amount of blood products transfused.

2. The safety defined as the incidence of new thromboembolic adverse events (TAE) (cerebrovascular accidents [CVA], myocardial infarction $[\mathrm{MI}]$, pulmonary embolism [PE], deep venous thrombosis [DVT], or arterial thrombosis). Screening for TAE was performed by physical examination. If a TAE was suspected, color duplex sonography, transesophageal echocardiography, computed tomography scan, and laboratory tests were performed to confirm the diagnosis.

\section{The secondary endpoints}

The secondary endpoints to compare both groups were regarding the following points:

1. All-cause mortality at 30 days postoperatively and at discharge

2. The incidence of surgical re-exploration

3. The need for multiple doses of rFVIIa

4. Days on mechanical ventilation

5. Length of stay (LOS) in ICU and hospital.

\section{Management of postoperative bleeding in Cardiac Surgical Intensive Care Unit and use of recombinant activated factor VIIa}

Figure 1 shows the protocol for management of postoperative bleeding in our CSICU. Exclusion of surgical causes of bleeding that requires re-exploration (cardiac tamponade, mediastinal hematoma, or large hemothorax) was done through clinical examination, hemodynamic monitoring, and radiographic tools including chest X-ray and bedside echocardiography, together with the consultation of attending cardiac surgeon. The usual dose of rFVIIa used in our CSICU is either; a full dose $(90-120 \mathrm{mcg} / \mathrm{kg})$ or a half dose $(40-50 \mathrm{mcg} / \mathrm{kg})$. Decision to administer either doses of rFVIIa was made after 
discussion between the ICU and surgical teams regarding options for further treatments, the risks associated with rFVIIa or re-exploration and hemodynamic state of the patient, according to the protocol in Figure 1. If a repeat dose of rFVIIa was needed, it would be of the same concentration as the first one.

\section{Statistical analysis}

Summary statistics is presented as medians with interquartile ranges. Group comparisons are done using Mann-Whitney U-test for continuous variables, and Fisher's exact test for categorical variables. All tests, $P \leq 0.05$ is considered statistically significant. Kaplan-Meir survival curve was estimated, and comparison between overall survivals in the two groups was done using log-rank test. Type 1 error rate was set at $5 \%$. SPSS version 17 (SPSS Inc, Chicago, Illinois). software was used to analyze the data.

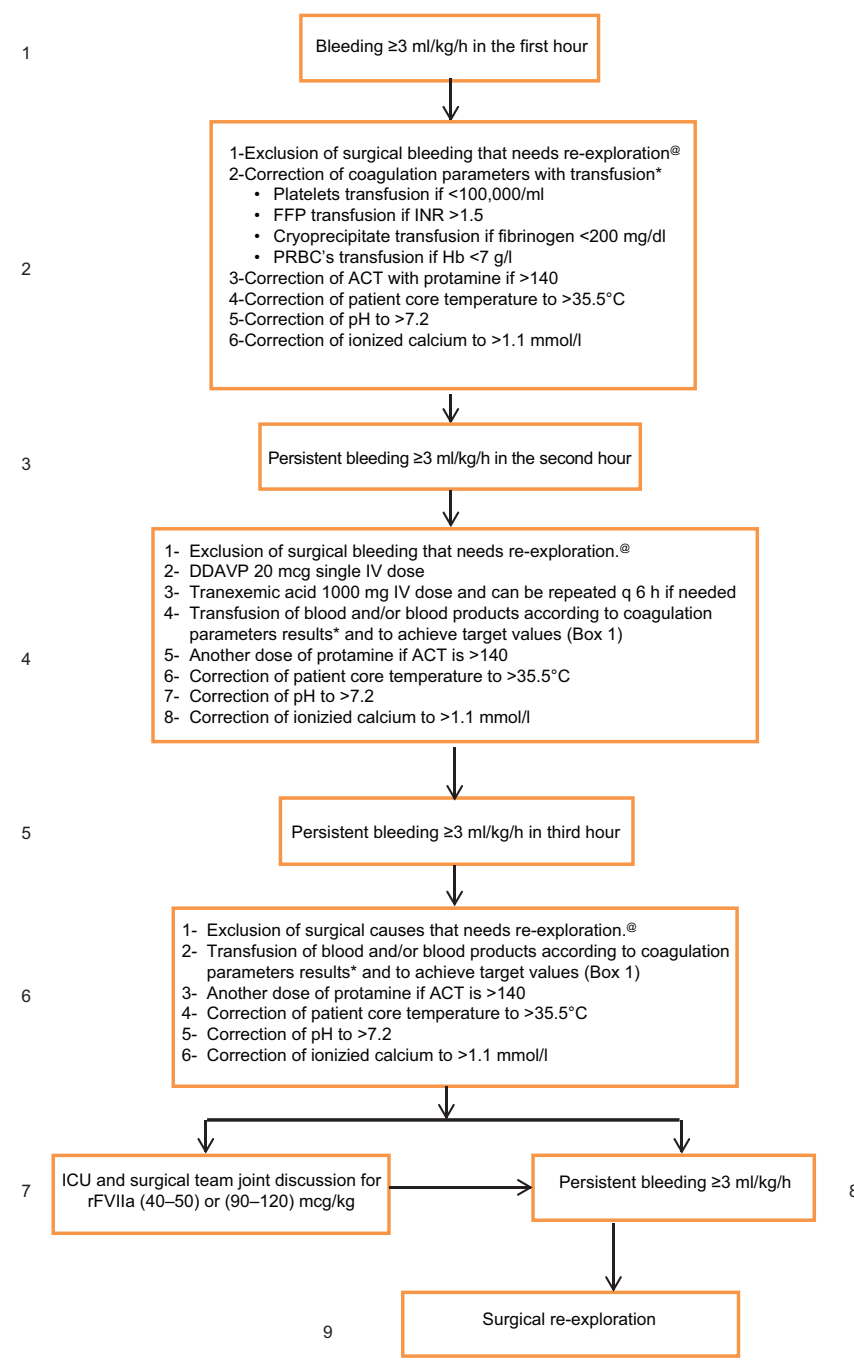

Figure I: Management protocol for bleeding postoperative patients in CSICU. @Exclusion of surgical bleeding that needs re-exploration according to Kirklin/ Barratt-Boys, $2013^{[31]}$. *Transfusion of blood products usually involved 2-4 units of platelets, 2-4 units of cryoprecipitate, I-2 units of fresh frozen plasma, and I unit of packed red blood corpuscles for each I $\mathrm{g}$ of hemoglobin $<7 \mathrm{~g} / \mathrm{L}$ at a time

\section{Results}

The medical records of all adult patients who had cardiac surgery done in the period from January 2004 to December 2014 were reviewed. Two hundred and eighty-seven patients were identified to have received rFVIIa for postoperative bleeding in CSICU.

Twenty-two patients were excluded due to rFVIIa administration in the operating room before CSICU admission. This administration of rFVIIa in the operating room was mainly based on the surgeon and anesthetist decision and not following the protocol in Figure 1. Three patients were also excluded for having corrective surgery for congenital heart disease, and 8 for being assisted with mechanical circulatory support. Ninety-eight patients were included into Group 1 (low-dose rFVIIa; $40-50 \mathrm{mcg} / \mathrm{kg}$ ), and 156 patients were included into Group 2 (high-dose rFVIIa; $90-120 \mathrm{mcg} / \mathrm{kg}$ ). There was no statistically significant difference in demographic and surgical characteristics of both groups [Table 1].

\section{Primary endpoints}

There was no statistically significant difference between the two groups regarding the reduction in chest tube bleeding in the first $6 \mathrm{~h}$ after admission to CSICU

\begin{tabular}{|c|c|c|c|}
\hline & Group I (98) & Group 2 (156) & $P$ \\
\hline$\overline{\text { Age }(\text { years) }}{ }^{\S}$ & $59(3 \mathrm{I}-77)$ & $61(26-72)$ & 0.7 \\
\hline Weight $(\mathrm{kg})^{\S}$ & $85(52-112)$ & $81(49-107)$ & 0.8 \\
\hline Male, $n(\%)$ & $63(64.3)$ & $97(62.2)$ & 0.8 \\
\hline Euro-score & $6.5(4-17)$ & $8(4-19)$ & 0.3 \\
\hline \multicolumn{4}{|l|}{$\begin{array}{l}\text { Preoperative comorbidity, } \\
n(\%)\end{array}$} \\
\hline Diabetes & $30(30.6)$ & $39(25)$ & 0.38 \\
\hline Creatinine $>1.4 \mathrm{mg} / \mathrm{dl}$ & $28(28.5)$ & $52(33.3)$ & 0.49 \\
\hline LVEF $<40 \%$ & $22(22.4)$ & $32(20.5)$ & 0.75 \\
\hline Previous MI & $19(19.3)$ & $26(16.6)$ & 0.6 \\
\hline Previous CVA & II (II.2) & $8(5.1)$ & 0.09 \\
\hline Pulmonary embolism & $2(2)$ & $0(0)$ & 0.14 \\
\hline Emergency surgery & $24(24.4)$ & $25(16)$ & 0.1 \\
\hline Redo surgery & $50(5 \mathrm{I})$ & $69(44.2)$ & 0.3 \\
\hline Preoperative anticoagulant & $38(38.7)$ & $46(29.5)$ & 0.13 \\
\hline Preoperative antiplatelet & $59(60.2)$ & $85(54.5)$ & 0.4 \\
\hline \multicolumn{4}{|l|}{ Type of surgery, n (\%) } \\
\hline Single valve & $23(23)$ & $28(17.9)$ & 0.33 \\
\hline Multiple valves & $40(40.8)$ & $47(30.1)$ & 0.1 \\
\hline CABG & $23(23.5)$ & $22(14.1)$ & 0.07 \\
\hline CABG with valve (s) & $22(22.4)$ & $20(12.8)$ & 0.06 \\
\hline Aortic surgery & $4(4.1)$ & $17(10.9)$ & 0.2 \\
\hline Heart transplant & $2(2)$ & $12(7.7)$ & 0.09 \\
\hline CPB time $(\min )^{\S}$ & $121(7|-| 67)$ & $133(69-176)$ & 0.4 \\
\hline Cross clamp time $(\mathrm{min})^{\S}$ & $84(53-119)$ & $106(62-153)$ & 0.6 \\
\hline Circulatory arrest time $(\mathrm{min})^{\S}$ & $17(13-28)$ & $23(15-36)$ & 0.1 \\
\hline
\end{tabular}

$\$$ Median and range, $n(\%)$. CPB: Cardiopulmonary bypass; CABG: Coronary artery bypass grafting; CVA: Cerebrovascular accident; MI: Myocardial infarction; LVEF: Left ventricular ejection fraction 


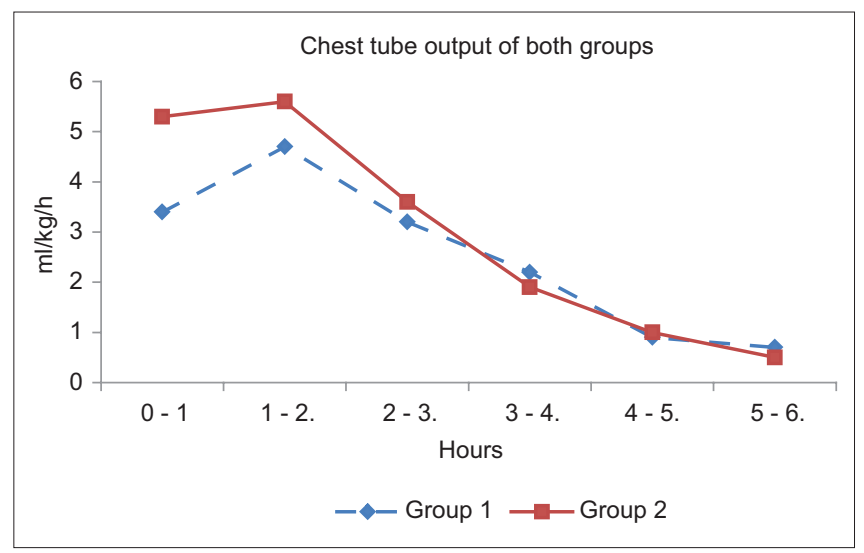

Figure 2: Chest tube output of both treatment groups in the first $6 \mathrm{~h}$ after admission to Cardiac Surgical Intensive Care Unit. No statistically significant difference between the two groups

[Table 2 and Figure 2]. The transfusion requirement also did not show statistically significant difference between the two groups in the first $24 \mathrm{~h}$ after CSICU admission [Table 3].

A total of 15 patients (5.9\%) had TAEs. Seven (7.1\%) patients in Group 1 (4 CVA and $3 \mathrm{MI}$ ) compared to $8(5.1 \%)$ patients in Group 2 (3 CVA, $3 \mathrm{MI}, 1 \mathrm{PE}$ and 1 DVT), $P=0.58$.

\section{Secondary endpoints}

There were no statistically significant differences of all-cause mortality at 30 days $(2[2 \%]$ in Group 1 vs. $5[3.2 \%]$ in Group 2, $P=0.6)$ and at hospital discharge between the two study groups (6 [6.1\%] in Group 1 vs. 13 [8.3\%] in Group 2, $P=0.5$ ), Figures 3 and 4, respectively. There was no statistically significant difference between the two groups regarding the incidence of re-exploration, need for multiple rFVIIa doses, and days on mechanical ventilation, CSICU, or hospital LOS [Table 4].

\section{Discussion}

In this report, the off-label low dose of rFVIIa (40-50 mcg/ $\mathrm{kg}$ ) was studied against the high dose $(90-120 \mathrm{mcg} / \mathrm{kg})$ in patients who had intractable postcardiac surgical bleeding. We did not observe any statistically significant difference between the two groups regarding the amount of chest tube bleeding in the first $6 \mathrm{~h}$ after CSICU admission, the number of blood products units transfused in the first $24 \mathrm{~h}$, new incidence of TAE, mortality at 30 days and at hospital discharge, need for re-exploration, days on mechanical ventilation, need for multiple doses, CSICU, or hospital LOS.

A few have reports compared the low-dose rFVIIa to conventional treatment of blood products and factors.

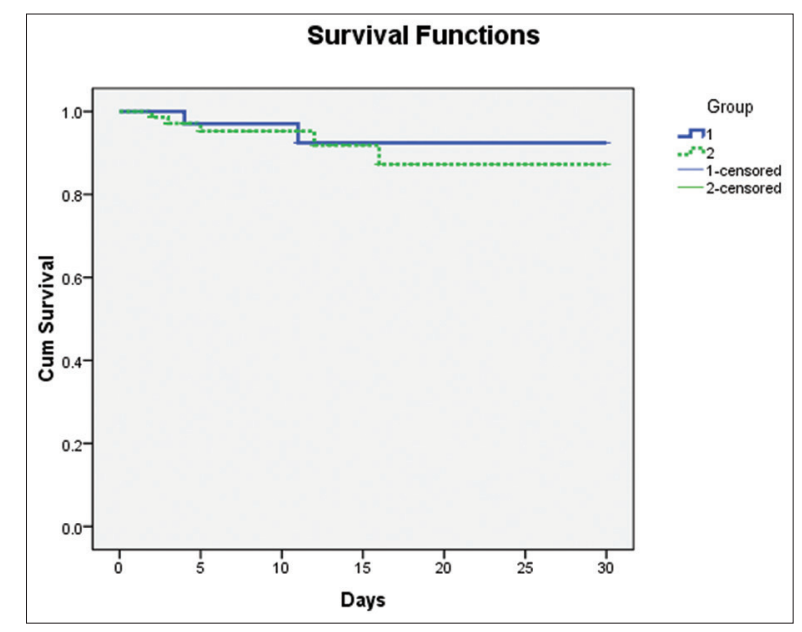

\begin{tabular}{lccc}
\hline \multicolumn{3}{c}{ Overall comparisons } \\
\hline & $\chi^{2}$ & df & Significant \\
\hline Log rank (Mantel-Cox) & 0.232 & I & 0.630 \\
Breslow (generalized & $0.28 \mathrm{I}$ & I & 0.596 \\
Wilcoxon) & & & \\
Tarone-Ware & 0.246 & I & 0.620 \\
\hline
\end{tabular}

Test of equality of survival distributions for the different levels of group

Figure 3: Thirty days mortality. Kaplan-Meier curve for survival among the two groups at 30 days after surgery

Table 2: Chest tube output in both treatment groups in Cardiac Surgical Intensive Care Unit

\begin{tabular}{lccc}
\hline & Group I & Group 2 & $\boldsymbol{P}$ \\
\hline $0-\mathrm{I} \mathrm{h}^{\S}(\mathrm{ml} / \mathrm{kg} / \mathrm{h})$ & $4.7(3.3-6.7)$ & $5.3(3.8-7.4)$ & 0.1 \\
$\mathrm{I}-2 \mathrm{~h}^{\S}(\mathrm{ml} / \mathrm{kg} / \mathrm{h})$ & $4.3(3.4-7.2)$ & $4.8(3.7-6.2)$ & 0.3 \\
$2-3 \mathrm{~h}^{\S}(\mathrm{ml} / \mathrm{kg} / \mathrm{h})$ & $3.4(2.1-5.8)$ & $3.7(2.5-6.5)$ & 0.9 \\
$3-4 \mathrm{~h}^{\S}(\mathrm{ml} / \mathrm{kg} / \mathrm{h})$ & $1.2(1.6-2.2)$ & $1.4(1.2-2.1)$ & 0.5 \\
$4-5 \mathrm{~h}^{\S}(\mathrm{ml} / \mathrm{kg} / \mathrm{h})$ & $0.9(0.3-1.8)$ & $I(0.6-1.7)$ & 0.8 \\
$5-6 \mathrm{~h}^{\S}(\mathrm{ml} / \mathrm{kg} / \mathrm{h})$ & $0.7(0.5-0.9)$ & $0.5(0.2-0.8)$ & 0.7 \\
\hline
\end{tabular}

$\$$ Median and range, $0 \mathrm{~h}$ is on admission

Table 3: Blood products requirements of the treatment groups in the first $\mathbf{2 4} \mathrm{h}$ after admission to Cardiac Surgical Intensive Care Unit

\begin{tabular}{lccc}
\hline & Group I & Group 2 & $P$ \\
\hline FFP (units) & $4(2-8)$ & $3(2-6)$ & 0.9 \\
Platelets (units) & $2(2-8)$ & $4(2-6)$ & 0.3 \\
Cryoprecipitate (units) & $2(2-4)$ & $2(0-4)$ & 0.5 \\
PRBCs (units) & $2(0-3)$ & $3(1-5)$ & 0.7 \\
\hline
\end{tabular}

$\$$ Median and range. FFP: Fresh frozen plasma; PRBCs: Packed red blood corpuscles

Brase et al. ${ }^{[19]}$ showed that low dose (median dose was $12 \mathrm{mcg} / \mathrm{kg}$, with a range of 3-62 mcg/ $\mathrm{kg}$ ) and early administration of rFVIIa was associated with significant increase in ventilator days, ICU LOS, but not inferior to standard therapy of blood and factor administration in reexploration rate. There was no increase in the risk of thromboembolism or acute kidney injury associated with rFVIIa administration. However, the definition of the bleeding they used is different from ours. The finding that rFVIIa patients received more blood product 


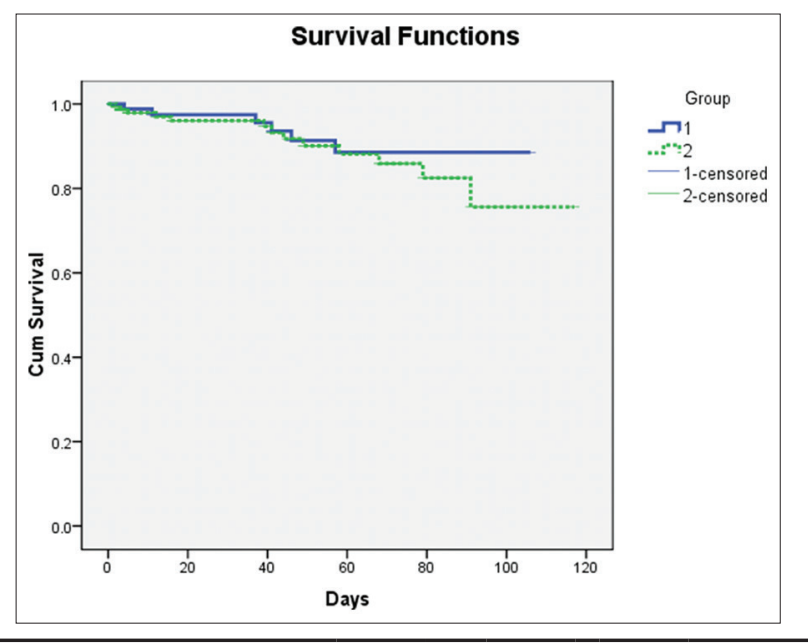

\begin{tabular}{lccc}
\hline \multicolumn{3}{c}{ Overall comparisons } \\
\hline & $\chi^{2}$ & df & Significant \\
\hline Log rank (Mantel-Cox) & 0.535 & $\mathrm{I}$ & 0.465 \\
Breslow (generalized & 0.276 & $\mathrm{I}$ & 0.600 \\
Wilcoxon) & & & \\
Tarone-Ware & 0.341 & $\mathrm{I}$ & 0.559 \\
\hline
\end{tabular}

Test of equality of survival distributions for the different levels of group Figure 4: Mortality at discharge. Kaplan-Meier curve for survival among the two groups at discharge from hospital

Table 4: Secondary endpoints of the treatment groups

\begin{tabular}{lccc}
\hline & Group I & Group 2 & $\boldsymbol{P}$ \\
\hline Re-exploration, $n(\%)$ & $4(4 . I)$ & $5(3.2)$ & 0.74 \\
Multiple doses, $n(\%)$ & $4(4 . I)$ & $3(1.9)$ & 0.43 \\
Postoperative mechanical ventilation (days) & $6(2-18)$ & $8(1-32)$ & 0.3 \\
CSICU stay (days) $^{\S}$ & $14(2-35)$ & $12(2-40)$ & 0.4 \\
Hospital stay (days) $^{\S}$ & $39(10-72)$ & $35(8-67)$ & 0.09 \\
\hline
\end{tabular}

\$Median and range. CSICU: Cardiac surgical Intensive Care Unit

transfusion than the matched control raises the concern of how the bleeding was controlled in the control group with less transfusion and without the use of rFVIIa which may lead us to think that the two groups were not well matched.

Payani et al. ${ }^{[20]}$ in a randomized clinical trial studied the effect of prophylactic use of low dose $40 \mathrm{mcg} / \mathrm{kg}$ rFVII on patients undergoing redo valve surgeries. They concluded that $40 \mathrm{mcg} / \mathrm{kg}$ of rFVII could be effective in reducing the volume of postoperative chest tube drainage and need for blood transfusion, with no thromboembolic event. Overall postoperative ICU stay was not different, while extubation was delayed in the placebo group.

Safani et al. ${ }^{[21]}$ in their analysis of outcomes of a low-dose rFVIIa protocol, they found that chest tube output declined from a mean of 350 to $85 \mathrm{~mL} / \mathrm{h}$ within 60 $90 \mathrm{~min}$ of rFVIIa administration. There were no arterial thrombotic events through discharge. Andersen et al..$^{[16]}$ compared low-dose rFVIIa administration $(<60 \mathrm{mcg} / \mathrm{kg})$ to propensity-matched control patients during complex thoracic aortic operations. Their findings suggest that rFVIIa led to fewer postoperative transfusions and no requirement for postoperative rFVIIa administration or re-exploration for bleeding. The safety profile of rFVIIa appeared promising, with few overall adverse events observed in the rFVIIa group and no apparent increase in adverse events compared with control patients.

Romagnoli et al. in two reports ${ }^{[22,23]}$ showed that small dose rFVIIa significantly reduced postoperative bleeding and patients needed less packed red cells, fresh frozen plasma, and platelet transfusion, and they had a reduced re-exploration rate, ICU LOS, and mortality. Two study patients had postoperative stroke, and in the remaining patients, no thromboembolic complication was detected. ${ }^{[23]}$ Van de Garde et al. ${ }^{[24]}$ found that rFVIIa dose of $40 \mathrm{mcg} / \mathrm{kg}$ stopped bleeding in seven patients who had uncontrolled bleeding after cardiac surgery.

On the other hand, the studies which compared low dose to high-dose rFVIIa were scant. Their conclusions are conflicting. Feih et al. ${ }^{[25]}$ found that there were no statistical differences in efficacy or safety between low-dose and high-dose rFVIIa for excessive bleeding following cardiac surgery. However, there were numerically higher rates of redosing with the low-dose group and rates of TEA with the high-dose group.

Alfirevic et al. ${ }^{[26]}$ underwent a dose-response analysis using multivariate logistic regression. He did not find any increase in the risk of mortality between high-dose $(>60 \mathrm{mcg} / \mathrm{kg})$ and low-dose $(<60 \mathrm{mcg} / \mathrm{kg})$ rFVIIa treatment groups.

Chapman et al. ${ }^{[27]}$ found no clear relationship between adverse outcomes and dose. It was difficult to make any conclusions about rFVIIa dose in this study, but it did seem to suggest that higher doses are not related to increased adverse outcomes.

Masud et al. ${ }^{[28]}$ performed a subgroup analysis on the potential dose effect relationship of each rFVIIa dosing quartile $>30 \mathrm{mcg} / \mathrm{kg}$. He found no significant differences in the magnitude of RBC reduction or percent of patients requiring massive transfusion among the quartiles. No adverse thrombotic episodes were noted, and the observed mortality (22.6\%) was not attributed to rFVIIa therapy. However, in that study, analysis was based on the magnitude of transfused $\mathrm{RBC}$ reduction, and not on bleeding. 
On the other hand, Hacquard et al. ${ }^{[29]}$ found a statistically significant association between the dose and bleeding outcomes. The mean dose infused in the group of patients with bleeding arrest was around $80 \mathrm{mcg} / \mathrm{kg}$, whereas the mean dose infused in the group of patients with sustained bleeding was around $65 \mathrm{mcg} / \mathrm{kg}$. Their data suggest that the most effective dose is at least $80 \mathrm{mcg} / \mathrm{kg}$. This allows only grade $\mathrm{E}$ recommendations according to the design of their study.

Gill et al. ${ }^{[14]}$ in a randomized placebo-controlled trial showed that $80 \mathrm{mcg} / \mathrm{kg}$ rFVIIa group was superior to $40 \mathrm{mcg} / \mathrm{kg} \mathrm{rFVIIa}$ group regarding decrease in both reoperations due to bleeding and drainage rate when compared to placebo. Both rFVIIa groups were almost equally superior to placebo regarding the blood transfusion volumes and the proportion of patients avoiding transfusions. Critical serious adverse events were almost the same in the two subgroups of rFVIIa although numerically but not significantly higher in the whole rFVIIa group compared to placebo.

Willi et al. ${ }^{[15]}$ extracted data from the hemostasis registry of The Australian and New Zealand registry that records cases of off-license rFVIIa. Univariate analyses compared patients receiving $\leq 40,41-60,61-80,81-100$, and $>100 \mathrm{mcg} / \mathrm{kg}$ of rFVIIa. They demonstrated no significant differences in the rate of TAEs, response to bleeding, or 28-day mortality.

Omar et al..$^{[30]}$ conducted a subgroup analysis for a group of patients received rFVIIa for uncontrolled bleeding. He showed that cardiothoracic surgery subgroup had $4.3 \%$ thrombotic events. At the multivariate logistic regression model, there were no independent predictors of the occurrence of thrombotic events in patients receiving rFVIIa. Mortality was unrelated to the occurrence of thrombotic events.

The limitations of this study are, first: being a retrospective study; it can only identify associations rather than cause-and-effect relationships and cannot exclude the role of unmeasured confounders in the observed associations. Second: the low-dose rFVIIa used in this study $(40-50 \mathrm{mcg} / \mathrm{kg}$ ) is not the lowest dose used in the literature. It is simply extrapolated from half dose of rFVIIa in hemophiliacs. There was no clear explanation why this particular dose is used and considered as low dose in our institution. Third: while the decision to or not to give rFVIIa for a bleeding patient usually followed a strict protocol, there was no clear objective reason for the choice of high or low dose rather than what we can say an expert opinion of the surgeon and the intensivist. This can be explained by heterogeneity among the patients; baseline risk, surgical complexity, and condition at the time of rFVIIa therapy (e.g., amount and rate of blood loss, hemodynamic status, and organ compromise). In addition, many cardiac surgeons and intensivists have been involved in this long duration of the study which may have led to variations in their triggers for administration of rFVIIa in addition to choice of the dose. On the other hand, the strength of the study arises from that the patients in our study were treated in a single institution according to standardized clinical guidelines. Moreover, our patient population was more homogeneous than in other published studies.

\section{Conclusion}

In this report, low-dose rFVIIa showed equivalent efficacy and safety to high-dose rFVIIa. Further prospective randomized studies are needed to confirm these findings.

\section{Acknowledgment}

The author would like to thank Dr. Raed Almehizaa, the clinical pharmacist of CSICU, and Shisamma Emmaneul, $\mathrm{RN}$ from the heart center research coordination office at King Faisal Specialist Hospital And Research Center, for their help, support, and being always available.

\section{Financial support and sponsorship} Nil.

\section{Conflicts of interest}

There are no conflicts of interest.

\section{References}

1. Dyke C, Aronson S, Dietrich W, Hofmann A, Karkouti K, Levi M, et al. Universal definition of perioperative bleeding in adult cardiac surgery. J Thorac Cardiovasc Surg 2014;147:1458-63.e1.

2. Karkouti K, Wijeysundera DN, Yau TM, Beattie WS, Abdelnaem E, McCluskey SA, et al. The independent association of massive blood loss with mortality in cardiac surgery. Transfusion 2004;44:1453-62.

3. Karkouti K, Wijeysundera DN, Beattie WS, Callum JL, Cheng D, Dupuis JY, et al. Variability and predictability of large-volume red blood cell transfusion in cardiac surgery: A multicenter study. Transfusion 2007;47:2081-8.

4. Society of Thoracic Surgeons Blood Conservation Guideline Task Force, Ferraris VA, Brown JR, Despotis GJ, Hammon JW, Reece TB, et al. 2011 update to the Society of Thoracic Surgeons and the Society of Cardiovascular Anesthesiologists blood conservation clinical practice guidelines. Ann Thorac Surg 2011;91:944-82.

5. Ferraris VA, Ferraris SP. Limiting excessive postoperative blood transfusion after cardiac procedures. A review. Tex Heart Inst J 1995;22:216-30.

6. Moulton MJ, Creswell LL, Mackey ME, Cox JL, Rosenbloom M. Reexploration for bleeding is a risk factor for adverse outcomes after cardiac operations. J Thorac Cardiovasc Surg 1996;111:1037-46.

7. Dacey L.J, Munoz JJ, Baribeau YR, Johnson ER, Lahey SJ, Leavitt BJ, et al. Re-exploration for hemorrhage following coronary artery 
bypass grafting: Incidence and risk factors. Northern New England cardiovascular disease study group. Arch Surg 1998;133:442-7.

8. Warren O, Mandal K, Hadjianastassiou V, Knowlton L, Panesar S, John K, et al. Recombinant activated factor VII in cardiac surgery: A systematic review. Ann Thorac Surg 2007;83:707-14.

9. Diprose P, Herbertson MJ, O'Shaughnessy D, Gill RS. Activated recombinant factor VII after cardiopulmonary bypass reduces allogeneic transfusion in complex non-coronary cardiac surgery: Randomized double-blind placebo-controlled pilot study. Br J Anaesth 2005;95:596-602.

10. Welsby IJ, Monroe DM, Lawson JH, Hoffmann M. Recombinant activated factor VII and the anaesthetist. Anaesthesia 2005;60:1203-12.

11. Yank V, Tuohy CV, Logan AC, Bravata DM, Staudenmayer K, Eisenhut R, et al. Systematic review: Benefits and harms of in-hospital use of recombinant factor VIIa for off-label indications. Ann Intern Med 2011;154:529-40.

12. Al-Ruzzeh S, Navia JL. Letter by Al-Ruzzeh and Navia regarding article, "Safety and efficacy of recombinant activated factor VII: A randomized placebo-controlled trial in the setting of bleeding after cardiac surgery". Circulation 2010;121:e234.

13. Hauser CJ, Boffard K, Dutton R, Bernard GR, Croce MA, Holcomb JB, et al. Results of the CONTROL trial: Efficacy and safety of recombinant activated factor VII in the management of refractory traumatic hemorrhage. J Trauma 2010;69:489-500.

14. Gill R, Herbertson M, Vuylsteke A, Olsen PS, von Heymann C, Mythen M, et al. Safety and efficacy of recombinant activated factor VII: A randomized placebo-controlled trial in the setting of bleeding after cardiac surgery. Circulation 2009;120:21-7.

15. Willis C, Bird R, Mullany D, Cameron P, Phillips L. Use of rFVIIa for critical bleeding in cardiac surgery: Dose variation and patient outcomes. Vox Sang 2010;98:531-7.

16. Andersen ND, Bhattacharya SD, Williams JB, Fosbol EL, Lockhart EL, Patel MB, et al. Intraoperative use of low-dose recombinant activated factor VII during thoracic aortic operations. Ann Thorac Surg 2012;93:1921-8.

17. White MC, Pryn SJ, Monk CR. Thrombogenic side-effects of recombinant factor VIIa after use in coronary artery bypass surgery. Anaesth Intensive Care 2006;34:664-7.

18. Nashef SA, Roques F, Sharples LD, Nilsson J, Smith C, Goldstone AR, et al. The EuroSCORE II study group. Eur J Cardiothorac Surg 2012;41:734-45.

19. Brase J, Finger B, He J, Wirtz K, Stun L, McMillen R, et al. Analysis of outcomes using low-dose and early administration of recombinant activated factor VII in cardiac surgery. Ann Thorac Surg 2016;102:35-40.
20. Payani N, Foroughi M, Dabbagh A. The effect of intravenous administration of active recombinant factor VII on postoperative bleeding in cardiac valve reoperations; a randomized clinical trial. Anesth Pain Med 2015;5:e22846.

21. Safani M, Drachenberg MR, Ferro ET, Hill SE, Thomas GS, Bethencourt DM. Low-dose recombinant activated factor VII (rFVIIa) for excess hemorrhage after cardiac operation. Ann Thorac Surg 2015;99:1865-70.

22. Romagnoli S, Bevilacqua S, Gelsomino S, Pradella S, Ghilli L, Rostagno C, et al. Small-dose recombinant activated factor VII (NovoSeven) in cardiac surgery. Anesth Analg 2006;102:1320-6.

23. Gelsomino S, Lorusso R, Romagnoli S, Bevilacqua S, De Cicco G, Billè $\mathrm{G}$, et al. Treatment of refractory bleeding after cardiac operations with low-dose recombinant activated factor VII [NovoSeven]: A propensity score analysis. Eur J Cardiothorac Surg 2008;33:64-71.

24. van de Garde EM, Bras LJ, Heijmen RH, Knibbe CA, van Dongen EP, Wiltink EH, et al. Low-dose recombinant factor VIIa in the management of uncontrolled postoperative hemorrhage in cardiac surgery patients. J Cardiothorac Vasc Anesth 2006;20:573-5.

25. Feih J, Rinka J, Ghadiali H, Kaiser M. High-versus low-dose recombinant activated factor VII use in cardiac surgery patients. Crit Care Med 2015;43(12 Suppl 1):152

26. Alfirevic A, Duncan A, You J, Lober C, Soltesz E. Recombinant factor VII is associated with worse survival in complex cardiac surgical patients. Ann Thorac Surg 2014;98:618-24.

27. Chapman AJ, Blount AL, Davis AT, Hooker RL. Recombinant factor VIIa (NovoSeven RT) use in high risk cardiac surgery. Eur J Cardiothorac Surg 2011;40:1314-8.

28. Masud F, Bostan F, Chi E, Pass SE, Samir H, Stuebing K, et al. Recombinant factor VIIa treatment of severe bleeding in cardiac surgery patients: A retrospective analysis of dosing, efficacy, and safety outcomes. J Cardiothorac Vasc Anesth 2009;23:28-33.

29. Hacquard M, Durand M, Lecompte T, Boini S, Briançon S, Carteaux JP. Off-label use of recombinant activated factor VII in intractable haemorrhage after cardiovascular surgery: An observational study of practices in 23 French cardiac centers [2005-7]. Eur J Cardiothorac Surg 2011;40:1320-7.

30. Omar HR, Enten G, Karlnoski R, Ching YH, Mangar D, Camporesi EM. Recombinant activated factor VII significantly reduces transfusion requirements in cardiothoracic surgery. Drugs R D 2015;15:187-94

31. Kouchoukos NT, Blackstone EH, Hanley FL, Kirklin JK. Kirklin/ Barrett-Boyes Cardiac surgery: Expert Consult. $4^{\text {th }}$ ed. Philadelphia: Elsevier Saunders; 2013. 